Revista de la red interuniversitaria de estudios sobre las literaturas rioplatenses contemporáneas en Francia

19 | 2018

La rebelión de los hijos: el judaísmo en la literatura latinoamericana contemporánea entre tradición y asimilación

\title{
Simja Sneh y León Poch: Presentes, en estado de memoria
}

Susana Poch

CpenEdition

Journals

Edición electrónica

URL: http://journals.openedition.org/lirico/6206

DOI: $10.4000 /$ lirico.6206

ISSN: 2262-8339

Editor

Réseau interuniversitaire d'étude des littératures contemporaines du Río de la Plata

Referencia electrónica

Susana Poch, «Simja Sneh y León Poch: Presentes, en estado de memoria », Cuadernos LIRICO [En línea], 19 | 2018, Puesto en línea el 20 enero 2019, consultado el 30 abril 2019. URL : http:// journals.openedition.org/lirico/6206; DOI : 10.4000/lirico.6206

Este documento fue generado automáticamente el 30 abril 2019.

\section{c)}

Cuadernos LIRICO está distribuido bajo una Licencia Creative Commons Atribución-NoComercialSinDerivar 4.0 Internacional. 


\title{
Simja Sneh y León Poch: Presentes, en estado de memoria
}

\author{
Susana Poch
}

\section{Contrapunto}

1 Simja Sneh (1908-1999) y León Poch (1913-2005) iniciaron, en distintos momentos y circunstancias, el trayecto del exilio desde su Polonia natal hasta Argentina, sin saber que habrían de encontrarse, no sólo entre sí y con un amplio territorio cultural para la creación, sino también con el desasosiego de vivir, en la nueva tierra, viejos/nuevos infiernos.

2 Poch llegó legalmente a Buenos Aires, con su familia, a fines de 1928. Sneh, único sobreviviente de la suya, entró como inmigrante ilegal en 1947. Poch, en Buenos Aires, usaba desde 1929, tinta, carbonilla y óleo para el ganapán y para dibujarse un lugar de pertenencia. Sneh fue "probablemente, el primer soldado judío de la Brigada [Judía] que también pretendía ser escritor y, más aún, escribir en ídisch" $(1975,7)$. Luchó y sobrevivió durante la guerra (y después), con la acción y el lápiz, a lo largo y ancho de los numerosos territorios que atravesó en Europa, Asia y América. Ambos fueron figuras de múltiples proyecciones que se desplazaron con aplomo por el espacio cultural, periodístico, artí stico judío y argentino, “con la naturalidad de los grandes” (Perla Sneh, 2006, 218).

Poch: dibujante, pintor, humorista, periodista, publicitario, escenógrafo de teatro ídish, muralista, escritor, ilustrador de tapas de libros y de revistas; diseñador de afiches y tapices. Colaboró con numerosas publicaciones en castellano e ídish como Crítica, Nervio, Patoruzú, Di Ídishe Tzaitung, La Luz, entre otras. Medalla de Oro de la Escuela Superior de Bellas Artes "Ernesto de la Cárcova". Ciudadano Ilustre de Buenos Aires, pintó y dibujó con amor y humor a su ciudad y a su gente tanto como al naciente Estado de Israel.

Sneh: Soldado, novelista, poeta, cuentista, dramaturgo, ensayista, cronista, periodista, traductor, editor de revistas, docente, investigador, conferencista, promotor de cultura. Colaboró con numerosas publicaciones en polaco, ídish, hebreo y castellano: Di Presse, La Nación, Mundo Israelita, La Prensa, Clarín, entre muchas. Faja de Honor de la S.A.D.E 
(Sociedad Argentina de Escritores) y eximio traductor de ídish, polaco, ruso, inglés, hebreo, castellano.

5 Ninguno de ellos teorizó acerca del guión, la yuxtaposición o la conjunción (Sosnowski, 1987). Eran judíos. Eran argentinos. Se conocieron en Buenos Aires, fueron amigos entrañables, incondicionales colaboradores y compañeros de ruta en muchos tramos. En 1952, Poch realizó la tapa del primer tomo (primera edición en ídish) de la trilogía autobiográfica y testimonial de Sneh, Na-ve'Nad (Sin Rumbo). También la portada de la obra de teatro, Dos gueshrei in der najt (El grito en la noche), en 1957, en la que aparece con su nombre en ídish, "Simje". Poch diseñó las tapas y dibujó viñetas de humor político para Alef, revista literaria bilingüe en ídish y castellano que Sneh fundó en 1961, con Aarón Yurkevich. Y realizó algunas tapas de Raíces. La revista judía para el hombre de nuestro tiempo , creada por Sneh en 1968. Por su parte, además de una amplia obra ensayística, testimonial y literaria, de traducciones, recopilaciones y de innumerables artículos periodísticos, Sneh escribió, en 1968, treinta y tres textos para el álbum Judíos de mi Infancia (Poch, 1968).

\section{El álbum, el corpus}

En junio de 1967, León Poch realizó una muestra, "Judíos de mi Infancia", donde expuso veintitrés dibujos, de $43 \times 32 \mathrm{~cm}$, realizados con tinta china. Dibujó, en negro, sobre cartones blancos, previamente "empastados" con papel mojado, produciendo una textura arrugada, áspera e irregular. Un año más tarde, Zwischo-Escuelas Scholem Aleijem public ó un álbum, encuadernado en tela, con treinta y dos ilustraciones, numeradas, en reproducción serigráfica, que mantenía el formato original de los dibujos aunque ya no su textura ${ }^{2}$. Se habían perdido la rugosidad, la aspereza. El álbum incluía una carpeta independiente que contenía una biografía de Poch y treinta y dos textos breves, todos escritos en ídish y traducidos al castellano por Simja Sneh. Las glosas estaban ordenadas según el número y el título que Poch le había dado a cada dibujo:

7 1) Schloime el changador / Schloime der treguer; 2) Alef...Bet... / Alef...Bet.../; 3) La novia / Di kale; 4) Invitado para el sábado / An oiraj oif shabes; 5) Jasidim / Jasidim; 6) Tumba de mi abuelo / Main zeidns matzeive; 7) Vendedora de roscas / Di beigl-hendlerke; 8) Invierno / Vinter; 9) Aguatero / Der vasertreguer; 10) Desplumadoras / Di flikerins; 11) ¡Compro!... i Compro!... / Handi!...Handi!...; 12) Músicos callejeros / Gasn-muzik; 13) Fiesta de la Torá / Simjas Toire; 14) El organillero / Der katerinshtchik; 15) Chicos / Kleinvarg; 16) Víspera del s ábado / Fraitik-tzu-najts ; 17) Tabernáculos / Sukes; 18) La linterna / Der Januke-lamtern ; 19) Preparativos para el sábado / Erev shabes; 20) Pan Ácimo / Matzes; 21) Actores / Blondszendike stern; 22) Filacterias / Tfilin; 23) Partida / Greit in veg arain...; 24) A la escuela / In shul arain; 25) Talmudista / Der masmid; 26) El escriba / Der soifer; 27) Baño ritual / In mikve; 28) Fin de sábado / Got fun Avrom...; 29) Purim / "A gutn Purim, malaj!"; 30) Mercado / Oifn mark; 31) El ricachón / Der guevir; 32) Musicantes / Di kapelie.

8 Al final del texto № 32, el nombre de Simja Sneh revelaba su autoría, que (¿descuido o acuerdo?) no figuraba ni en la tapa ni en el colofón. Indudablemente, no se trataba de una coautoría aunque sí de un trabajo realizado en colaboración. 


\section{La gran desilusión}

9 En la década del '60, ya no les era posible ni a Poch ni a Sneh, ni a la comunidad judía argentina, desviar la mirada: la Argentina del "crisol de razas", idealizada en 1910 por Alberto Gerchunoff (1884-1950), mostraba aterradoras grietas. Grupos de choque nacionalistas -Tacuara, Unión Cívica Nacionalista, Guardia Restauradora Nacionalista- se lanzaron a una escalada antisemita de una violencia directamente proporcional a la impunidad que gozaban. El antisemitismo "literaturizado", que históricamente había acompasado acciones concretas, aún estaba vigente, por supuesto. Seguían allí los libros de José María Miró (a) Julián Martel (1867-1896), Eugenio Cambaceres (1843-1889), Manuel Gálvez (1882-1962), Gustavo Martínez Zuviría (a) Hugo Wast (1883-1962). Viejas y nuevas publicaciones nacionalistas de derecha ganaban lectores. Pero otra "escritura", agresivamente performativa, apareció en todo el país: bombas de alquitrán y pintura lanzadas a los frentes de edificios comunitarios; leyendas antijudías e iconografía antisemita; svásticas, cartas y amenazas escritas; profanación de cementerios, secuestros, atentados, violencia física; una cruz gamada tatuada en un pecho; asesinatos.

El espacio de seguridad que la retórica y la literatura judía y argentina habían formulado era una ilusión. Para Gerchunoff, "acá", Argentina, era la Tierra Prometida, la Nueva Sión; y "allá", Europa, la tierra del exterminio y la violencia (Viñas, 1964, 300). En los primeros años del '60, esta dicotomía se invierte. El terrible “allá”, el de Europa, está ahora, dramá ticamente inscripto "acá", en la Argentina de Gerchunoff. Los judíos de Argentina tienen la dolorosa pero más realista percepción de que el terror de "allá" llegó "acá".

11 El secuestro de Eichmann (1960), su juicio (1961) y ejecución (1962) abrieron las compuertas para comenzar a captar lo que representó la Shoáh, pero también hizo que los grupos nacionalistas sumaran una nota antiisraelí a su tono antijudío. La Guerra de los Seis Días, pocos años más tarde, dio pie para que la derecha retomara la retórica de la doble lealtad y de la nación amenazada por la traición del "sionismo apátrida", una de "las fuerzas extrañas" que tanto temía Leopoldo Lugones (1874-1938).

Las fracturas de la integración estaban expuestas. Pero esas mismas fracturas llevaron a la comunidad judía a emprender un doble recorrido. Uno, hacia la calle no judía, en busca de apoyo y solidaridad; el segundo, hacia el interior de la comunidad, tendiente a dar nuevos ímpetus a la educación y la cultura judías, y al sionismo. En esta doble articulación se inscriben la creación y publicación del álbum Judíos de mi Infancia.

\section{Las vísperas de las vísperas}

13 En el capítulo 1 del primer tomo de Sin Rumbo ( $N a$ ve'Nad), "En vísperas de la tormenta", Sneh le dedica unas pocas páginas al verano de 1939. Describe "los rumores inquietos que, posándose sobre el corazón de la gente, envenenaron la atmósfera con malos presentimientos" y que "durante todo el verano aletearon sobre Polonia [...]" (1993, p.17). Los dibujos de Poch se lanzan hacia las vísperas de las vísperas. Hacia el vacío y la representación del vacío que dejó al marcharse de Polonia en 1928. Ni siquiera el arte que le abría ilimitadas posibilidades para enfrentar y expresar la realidad- le permitió a Poch, durante casi cuarenta años, plasmar sus "pesadillas por no haber estado allí", como 
me dijo una vez. Pesadillas sin imágenes, que no se dejaban dibujar, que aparecían, de noche, en el cuerpo, entre sudores, quejidos y calambres.

¿Cómo representar lo no representable? Él no había estado "allá". De modo que el único camino que tenía, para superar el terror que, en los '60, estaba "acá", era recuperar su mundo, el de los días anteriores al exilio, aquel sobre el cual, alguna vez, había posado la mirada. Recurre a su reservorio de imágenes. Se distancia de ellas, selecciona y combina los recuerdos, establece principios temáticos y técnicos. Sabe que el pasado no puede ser recuperado tal como fue, ni siquiera tal como lo vio o vivió sino deformado, alterado. Lo representa arrugado por la técnica de papel empastado y con duras trazas en tinta china. Con figuras agarrotadas (como sus calambres). Seres sin color, sin lugar y sin nombres propios. Siente que su pasado fue vaciado por la Shoáh, invisibilizado, y que su lugar natal, Sosnowiec, se transformó en un no-lugar, también sin nombre. Ni siquiera aparece en la biografía que Sneh escribió, donde sólo dice que es "argentino, oriundo de Polonia".

El espacio donde ubica a sus judíos y a su infancia es el compendio de todos los lugares o compendio de todos los vacíos, compartido por Sneh: “¿Qué es lo que ha quedado de esa Polonia? Cenizas, ruinas y odio... [...] El lejano hogar polaco se ha alejado más aún; se ha tornado inalcanzable, perdido casi para siempre." (1993, vol.2, 123). El no-lugar convierte a las figuras en arquetipos; y los personajes anónimos, filosófica y ontológicamente, se tornan hipóstasis. Poch usa, entonces, la página blanca como el lugar del no-lugar. Y sobre ese no lugar traza, negro sobre blanco, un registro, un archivo de la memoria.

"Este libro es mi autobiografía sin ser, en absoluto, la historia de mi vida", dice Sneh en El pan y la sangre (1977). En el mismo tono juegan los autorretratos recurrentes de Pochniño, en clave autobiográfica, que se entretejen con los personajes de su infancia. Pero el más curioso es un autorretrato no de Poch-niño sino adulto. Adulto en su infancia. Poch es el flautista de la última ilustración de la serie, "Musicantes/Di kapelie". Es él y es otro. O, en realidad, ya no es. Ni él, ni otro. Sólo un mapa, que no es el territorio, del niño que llegó a ser adulto "acá", pero también del niño que fue destruido y que no llegó a ser adulto, "allá". Quiere representarse tal como hubiese sido si se hubiese quedado. $O$ como no hubiese sido si se hubiese quedado... Una materia que existe pero no existió, tatuada sobre el papel. Un dibujo, negro, sobre una página en blanco de aquel que pudo haber sido; del que fue; del que no pudo ser o del que ya no está más. 


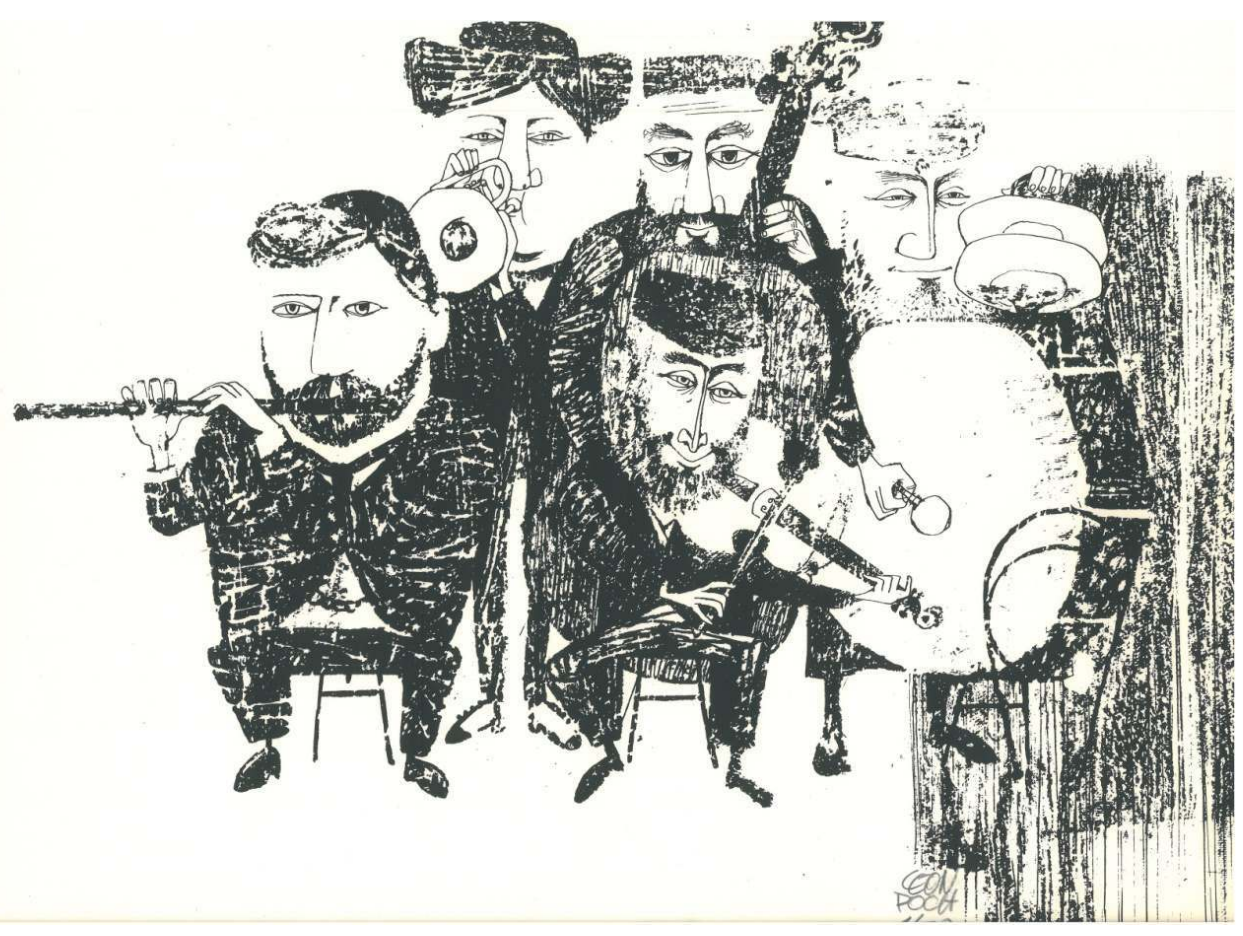

32. Musicantes / Di kapelie

\section{Escribir en ídish}

Componer un texto para cada ilustración lo lleva a Sneh a enfrentar una lucha en varios frentes de los que sólo señalaré algunos: 1) Interpretar un complejo sistema de signos pictóricos y "traducirlos" a un complejo sistema de signos lingüísticos. 2) Optar por una de las varias lenguas judías: el ídish. 3) Traducir al castellano sus propios textos. 4) Decidir acerca de la transliteración al castellano de términos del ídish"

Sneh navegaba con naturalidad y solvencia, por varias lenguas, aunque el ídish, la íntima, la de las masas populares, era la suya, la lengua materna.

Desde el siglo XI el ídish fue, junto con el hebreo y el arameo, el idioma de los judíos de las regiones de Europa Central y del Este, conocidas como "Ashkenaz". Formidable medio de comunicación oral y de creación literaria, se desplegó por las más amplias fronteras del mundo. Provino de dialectos medievales recombinados, de diferentes regiones alemanas, y se lo denominaba "Jiddisch-Teutsch", "judío teutónico". Al comienzo, siguió el modelo gramatical del alemán, pero a lo largo de los siglos desarrolló cambios en la sintaxis, la morfología y el léxico. Sumó términos y expresiones del hebreo, arameo, lenguas eslavas, latinas, griegas, romances y de cada región en que la lengua y sus hablantes anclaban. Se lo escribe con letras hebreas y algunos signos diacríticos aunque no mantuvo la escritura hebrea, sin vocales. Optó por un sistema casi fonético de escritura, si bien respeta la ortografía original de las palabras hebreas y arameas que incorpora. Surgió como idioma de origen popular, con proyecciones de inclusión y objetivos pedagógicos: “[...] destinado a esclarecer lo santificado y lo complicado y hacerlo accesible al judío simple, carente de educación más alta, y en primer término a la mujer judía, que por regla general era excluida del sistema educativo judío." (Sneh, 1976, 15). 


\section{Para quién escribir}

"Poch devela el exótico-lejano, y para nosotros todos tan cercano, país de su infancia, que fue también la infancia de todos nosotros [...]", dice Sneh en una nota que escribió con motivo de la muestra de $1967^{5}$. Distingue un "ellos" para quienes el mundo representado resultaba lejano, exótico, y un "nosotros", integrado tanto por aquellos que vivieron experiencias similares como por los que se reconocían en una memoria compartida.

21 Existía, en ese momento, en el mundo, una audiencia ídish parlante y lectora, y otra, que sabía hablar ídish pero no leerlo. Además, un público hispano parlante, judío o no, que desconocía totalmente el ídish, pero compartía la memoria; y que se diferenciaba de aquél, judío o no, que ignoraba tanto el ídish como el mundo del shtetl, villorio judío polaco. A "ellos" y a "nosotros": a todos se proponían llegar Poch, Sneh y la Editorial Zwischo-Escuelas Scholem Aleijem.

Si bien acceder a un público extendido era el objetivo más visible, otras preocupaciones aquejaban a los autores y a la Editorial. Poch exteriorizaba, en numerosas viñetas, su inquietud por la paulatina desaparición del ídish de la vida judía en la Argentina. Sneh era conciente de que escribía "en una época en que el idioma idisch pierde cada vez más el carácter de lengua hablada", y de que "urge la necesidad [de traducir] las obras literarias concebidas en ese idioma." (1975, 21) Además de expresarse en su lengua materna, escribir en ídish significaba, por un lado, vivificar la lengua asesinada en la Shoáh y, por otro, recobrar parte del espacio que le había quitado el programa sionista al imponer el hebreo como paradigma de su política homogeneizadora. Si bien había sido recuperada parcialmente en la voz de algunos testigos en el juicio a Eichmann, Sneh discrepa con “ una crítica literaria hebrea que por lo general no se muestra muy amistosa hacia la creación cultural en idish" $(1975,16)$.

Zwischo-Escuelas Scholem Aleijem publica cuando la ruptura de la transmisión ya es evidente: las escuelas judías están por eliminar totalmente la enseñanza del ídish de sus programas. Insuflar aire a un proyecto educativo idishista que agoniza es un imperativo para la Zwischo. Todos ellos saben que, en breve tiempo, la literatura ídish en Argentina no tendrá escritores. No tendrá lectores. O tendrá pocos. Escribir en ídish no es el intento de un retorno al origen (el retorno es imposible) ni de dotar de voces a judíos que fueron forzados a enmudecer. Es la expresión de un deseo: que el pasado, arrasado, vacío, sordo y mudo no se transforme en un lugar de memoria abandonado.

\section{Las preguntas}

Para Sneh, este deseo instaura una serie de preguntas que atraviesan su historia y casi todos los textos del álbum. La incertidumbre adopta la forma de una adivinanza, un misterio, o un enigma sin resolver; un doloroso y pesado acertijo sin solución:

[...] ¿Por qué de bultos tan grandes le quedan solamente algunas míseras monedas?... [...] los que estudian la Torá... Tal vez ellos puedan resolver este misterio... (1)

¿Quién resolverá el misterio de su silenciosa melancolía?... (3)

Y, ¿qué se le va a hacer? Quizás el rabí, ¡Largos años viva! posee la clave para descifrar su silencioso diálogo... (5) 
dos signos de puntuación como marca estilística para transmitir dudas, conjeturas, indecisiones, indeterminaciones. Puntos suspensivos que abren y cierran cláusulas que ni se abren ni se cierran. Signos de admiración que enfatizan y tratan de representar en la escritura las fuertes líneas negras del dibujo. Se reiteran los adverbios modales "tal vez" y "quizás", que llevan implícita la noción de posibilidad y que proyectan el deseo de encontrar una clave/llave. La frase aseverativa queda eclipsada por las dubitativas. La interrogación como cierre o como apertura se reitera, casi de manera obsesiva, al mismo tiempo que expresa resignación ante la falta de respuesta.

Mai ko mashma lon, dice la frase talmúdica en arameo que significa "¿para qué hacernos escuchar algo que no tiene nada nuevo que decir o que fue dicho basándose en un error?" La pregunta resuena en Sneh como un eco del poema de Abraham Reisen (1876-1953) ${ }^{7}$. Sin embargo, si bien la expresión sostiene que nada se puede "escuchar" de lo obvio, también señala que nada es tan obvio o mudo que no pueda contener un nuevo sentido: siempre se impone atender a la palabra que se hace oír. La palabra, entonces, en las múltiples lenguas en las que se exprese el artista, será una posible llave para ordenar y organizar los diálogos asesinados; los misterios y emociones que producen las imágenes quebradas, las palabras en suspenso.

\section{De la imagen a la palabra}

El paso más complejo es la écfrasis (poética, en este caso), recurso que permite construir descripciones, narraciones e interpretaciones a partir de una imagen. Va de suyo que más que una "traducción" se produce una transmutación. Sneh no transcribe en palabras la obra plástica, sino que ésta se convierte en pre-texto de su creación literaria. Hay una $b$ úsqueda de tiempos, lugares, voces y personajes en su propia "vísperas de las vísperas", aquellas de las que tan poco escribió en su monumental obra autobiográfica. Nos ofrece una visión de la vida y del mundo que él también perdió y añora:

[...] [al mirar los dibujos de Poj] he sentido que regresé al país de mi propia infancia. Del lejano-cercano cercenado pasado nuestro ha resurgido el shtetl judío polaco, vivo, adornado con todas las gracias judías, exaltado con el fino núcleo azulino de la memoria nostálgica, que nos atrapa siempre cuando recordamos a nuestros queridos y cercanos, que se alejaron de nosotros y sin embargo viven en nuestro espíritu. Es difícil decidir, además, si se trata más de una añoranza hacia todos ellos, los que viven en el país de las sombras de nuestras noches insomnes o si es la añoranza por nuestra propia y para siempre perdida infancia. Pero sea como fuere sabemos que hasta el último aliento nuestro, cargamos con un mundo entero de imágenes, sensaciones y sentimientos ${ }^{8}$.

Escribe, se asume como poeta, toma distancia de los dibujos, los modifica. Introduce el color que había sido desterrado por Poch de su territorio plástico. En invierno, dice, "el aire es azulino [...]" (8), como la memoria nostálgica. Se vuelve verde y dorado en la fiesta de los Tabernáculos cuando "a través del verde techo de la cabaña penetra el áureo centelleo de las estrellas." (17) "Rojo es el terciopelo" de la Torá; roja la llamarada del monte Sinaí, y el "enrojecido júbilo [...] de roja sangre judía”. (13)

No se deja intimidar por las limitaciones de espacio. Si bien cada viñeta debe acotarse a, aproximadamente, 80 palabras en cada lengua, logra dotar a sus personajes de voz propia apelando al discurso directo, al indirecto, al indirecto libre y al monólogo. Narra, 
describe, reflexiona. Crea una atmósfera emocional. Comparte opiniones, miedos, deseos de venganza, desesperanza. Compromete al lector, lo involucra.

Juega con el tiempo. Introduce el presente en el pasado cuando dice "en aquel tiempo no existía la radio" (12). Unifica el tiempo del enunciado pictórico con el tiempo de la enunciación escrita como si el representado en la imagen, el de la escritura y el de la lectura se actualizaran en su presente.

En "Tumba de mi abuelo" (6), asume la voz de un niño, difuminado en el dibujo pero que se hace cargo, en el presente de la enunciación, de la única referencia explícita a la Shoáh: "...Los nazis destruyeron todas las tumbas [...]."

Imagen y texto dialogan, se complementan. Podemos, si queremos, ver las figuras al mismo tiempo que leemos. Porque cuadros y textos están ahí, presentes. Y esta es una de las potencias del álbum: juntas, imagen y palabra se alían para derrotar al vacío.

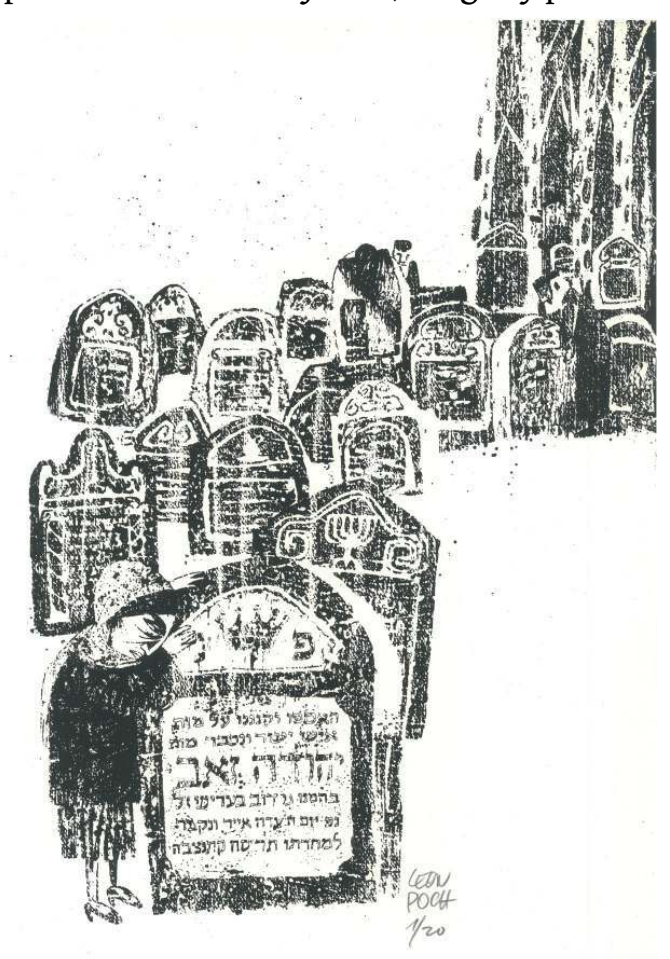

6. Tumba de mi abuelo / Main zeidns matzeive

\section{¿Cómo suena el ídish?}

La vastedad del territorio en los que se expandió el ídish dio lugar a que se formasen variantes dialectales. En Europa del Este, surgieron, básicamente, tres: lítvish (lituano); ucrainish (ucraniano) y poilish-galitzianer (polaco-galitziano). Si bien la mayoría hablaba la variante polaca, las que se impusieron como formas "cultas" fueron el lituano -como lengua estándar para la vida académica, literaria y pedagógica- y el ucraniano, para el teatro. Dado que la decisión se sustentaba en políticas nacionales y proyectos culturales que tuvieron lugar en el siglo XIX, tanto en el mundo judío como en el no judío, para muchos resultaba arbitraria la decisión de establecer como variante suprarregional "correcta" al lituano, el dialecto con menor número de hablantes. Miraban con 
desconfianza a la elite lituana "esclarecida" que aspiraba a orientar el destino de las comunidades judías. Esta elite, por su parte, consideraba con cierto desdén a las masas “ populares". (Weinreich, 1992. Katz, 2010) construir un camino hacia afuera, para llegar a la audiencia ídish e hispano parlante a la que aspiraba a acceder con sus textos. Respecto de la lengua y sus dialectos, mantiene una voluntad integradora y procura trascender las disputas dialectales. Veamos cómo: Cuando se trata de la realización escrita de un término que pertenece al hebreo, no surge ningún problema. El ídish se escribe con alfabeto hebreo y el léxico hebreo incorporado no modifica su escritura: se mantiene igual. Por lo tanto, la palabra "matzot" (pan ácimo) que se escribe, en hebreo, sólo con las consonantes, $m$-tz-t, se mantiene tal cual en ídish escrito. "Shabat" (Sábado) se escribe en ambas lenguas sh-b-t, sin las vocales. ¿Tan simple? Sí, por supuesto. carece de vocales escritas, de modo que es posible (y los dialectos del ídish lo hacen) modificar la pronunciación. ¿Cómo pronunciar las vocales "ausentes" de $m$-tz-t? ¿Matzot (hebreo), motzes (ucraniano) o matzes (lituano)? ${ }^{10}$ ¿Cómo pronunciar las de sh-b-t? ¿Shabat (hebreo), shabes (lituano y polaco) o shobes (ucraniano)? Si, como dije antes, diferencias culturales generaban roces entre los distintos grupos, la elección de una variante o de otra no era irrelevante. Más que apuntar a la brecha, Sneh prefirió ver dónde se intersectaban y se "enganchaban" en tanto modalidades diferentes con visiones de mundo diferentes. Por eso, Sneh siempre opta por la transliteración hebrea shabat, que alterna con la traducción castellana, "sábado". Del mismo modo, cada vez que aparece el término hebreo Torá, evita la transliteración ídish, Toire. La hebrea surge como superadora de las diferencias. Como el espacio lingüístico compartido por todos.

En el juego de las transliteraciones, que podría obligarlo a manifestar su pertenencia y/o preferencia por alguno de los dialectos, Sneh se ubica más allá de ellos. Cada vez que elige no elegir, aparece un "supraídish" ideal, representado por la realización sonora hebrea, que se extiende como un manto protector sobre las diferencias, neutralizándolas. Un ídish tan arquetípico como los personajes de Poch, y, al mismo tiempo, tan peculiar como ellos. Más allá de cómo cada ídish parlante pronuncia la lengua, Sneh pareciera creer que 
puede existir una instancia lingüística, histórica, superior y englobadora, que reconcilie los disensos sin que se pierdan las especificidades. $O$ una instancia que reconozca el derecho a la multiplicidad de lenguas y variantes. Y esto vale también en la andadura del ídish de Sneh puertas afuera.

\section{Puertas afuera}

La autotraducción representa un cruce de fronteras. No sólo debido a que un mismo autor asume el poder sobre dos lenguas para dirigirse a audiencias diferentes, sino porque este "poder" (en todos los sentidos de la palabra) marca los contornos personales, ideológicos y políticos de un modo de organizar y reorganizar las relaciones entre diferentes lenguas, tradiciones e instituciones literarias. A Sneh, autodidacta del castellano pero multilingüe e intrépido, no le tembló la pluma cuando se lanzó en el campo de batalla cultural, donde se daban brutales enfrentamientos para definir la literatura y el idioma de los argentinos ${ }^{11}$.

40 La batalla lingüística y literaria no era sólo una polémica entre intelectuales, académicos y escritores. También era la expresión de las profundas transformaciones que se estaban produciendo en la sociedad y en la cultura. Por supuesto, los límites no siempre estaban claros. Debido a la variedad de posturas de los intelectuales y artistas que debatieron estas cuestiones, se producían contradicciones, deslizamientos y entrecruzamientos de clase, políticos, ideológicos, culturales y artísticos muy complejos.

41 Sobre este entramado se tejen los textos de Sneh en castellano y es posible ver el modo peculiar en el que se "acomodan" en el castellano. La expresión coloquial, cariñosa, familiar del ídish es sustituida por un castellano considerado "culto". No solamente como opción estética sino que la decisión parece decir: "Tengo derechos de lengua; me encuentro "acá"; reivindico mi pertenencia."

Utiliza términos hispánicos y literarios: "ignotos", “empero", “diablejo”; transforma la popular canción de Itzik Manguer (1901-1969), di goldene pave, en una formulación casi modernista, "el áureo pavo real" (21). Con lucidez, entiende los matices de los diminutivos. Si bien en ídish son de uso muy frecuente, con un valor afectivo y cariñoso intenso, en castellano pueden asumir connotaciones despectivas o resultar en un estilo infantilizado. Por eso traduce ídish vaibl no por "mujercita" sino "mujer judía" (3) o "di epelej oif di fendlelej fun di jeider-inguelej hobn roite bekelej / Las manzanas (manzanitas) que coronan las banderitas de los escolares (alumnitos) judíos tienen mejillas (mejillitas) rosadas (rosaditas)" (13) (el subrayado indica los diminutivos y las palabras entre paréntesis, la traducción que no eligió).

43 Tal vez, algunas decisiones como traductor se originan en la idea de que el lenguaje cotidiano rompe normas estilísticas. Y que, además, tiende a vulgarizar al objeto denotado. Precisamente lo contrario de lo que el álbum se proponía. La lengua familiar ídish es transportada a un nivel elevado en castellano, tanto por el imperativo retórico del medio cultural al que pertenece o aspira pertenecer el escritor, como porque transmite, indirectamente, el juicio de valor que tiene sobre el mundo que describe. La fluidez del ídish se vuelve, en castellano, intensa y vehemente voz que exige, demanda ser leída, ser reconocida. A pesar de que, en 1968, la escritura de Sneh aún manifiesta la presencia del antiguo español como marca de legitimidad, ya está tomando fuerza su castellano rioplatense, el de "la muchachada" (González, 2015, 19) y "el changador" (1) Y 
si bien no echó raíces, en su prosa, el criollo, el del "payador", (Sneh, 1975, 11), falta poco para que Gudiño Kieffer diga: “es uno de los nuestros” (Perla Sneh, 2015, 28).

\section{“...sabemos que hasta el último aliento nuestro, cargamos con un mundo entero de imágenes, sensaciones y sentimientos"}

La primera imagen del álbum y el primer texto, Shloime der treguer / Schloime el changador, condensan el sentido de "estos enormes pesados bultos" (1) que Poch y Sneh decidieron cargar. Si, como dice Walter Benjamin $(1991,124)$, el recuerdo funda la cadena de la tradición que se transmite de generación en generación; si funda la red compuesta por todas las historias que se enlazan una con la otra, entonces las treinta y dos imágenes y los sesenta y cuatro textos asumen la responsabilidad del recuerdo. Por lo menos, parte del recuerdo. De un tiempo, un lugar y una lengua. Si muy pesada es la carga de fundar mucho más dura es la de reparar la cadena de la tradición, la "cadena de oro", di goldene keit como la llamó Peretz, quebrada no sólo por la catástrofe histórica de la Shoáh sino también por el peligro que representa el olvido. No es la nostalgia del pasado la que soportan estos textos-imágenes sino la incertidumbre del futuro.

Poch siente la responsabilidad de conjurar el olvido trazando, negro sobre blanco, espacios vaciados y seres silenciados. Sneh, la de escribir en ídish para devolver su lengua a personas con las que ya no podrá dialogar. Y Zwischo-Escuelas Scholem Aleijem publica para fijar, en el tiempo y en el espacio, los restos de ese pasado; para crear, con un instrumento artístico y didáctico, un lugar de memoria.

El changador -simbiosis entre un mítico rey Salomón (en ídish, Schloime) y un mitológico titán Atlas- transforma su bulto en un álbum-templo-mundo, de imágenes, sensaciones, sentimientos y de un idioma que se enfrenta al abismo del silencio. Sus ojos nos miran de frente y nos atraviesan; ojos tristes, lúcidos aunque un poco desviados, tal vez agobiados por llevar sobre los hombros un álbum/fardo/destino, humano y judío, que habrán de cargar hasta el último aliento. ¿Manifiesto o testamento? No lo sé. Pero, en la medida en que Poch y Sneh transforman sus experiencias individuales en una obra artística, ésta se torna acontecimiento colectivo y adquiere dimensión política, ética y simbólica. Serán las generaciones ulteriores las que habrán de conferirle una supervivencia duradera. $\mathrm{O}$ el olvido. 


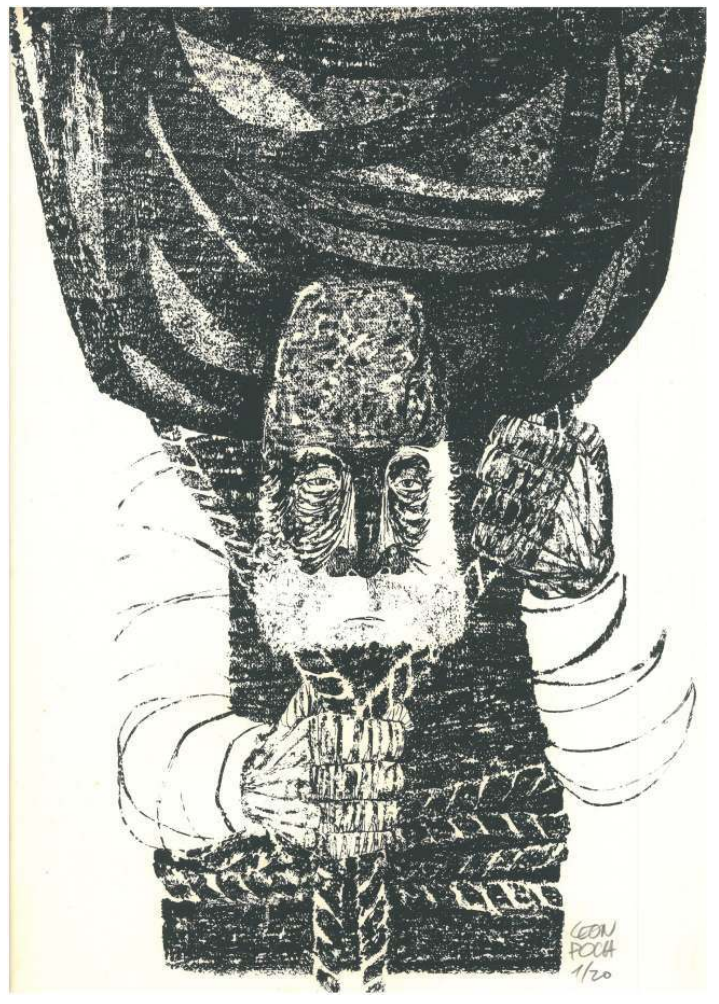

1. Schloime el changador / Schloime der treguer

\section{A modo de final, pero no}

47 ¿Dónde está el álbum hoy, 50 años después de su publicación? ¿Quién lo conoce, lo mira, lo lee? ¿Qué maestro lo usa como material didáctico? No puedo evitar cierta pesadumbre cuando me hago estas preguntas porque intuyo las respuestas. León Poch era mi padre; Simja Sneh, maestro, amigo y colega. El álbum, una parte importante de mi vida, tanto como sus creadores, sus judíos, su ídish y su castellano.

Hoy reflexiono y escribo acerca de esta obra porque entiendo que todavía se abre a nuevas preguntas y respuestas que, aunque me generen inevitable angustia, pueden proporcionar una comprensión más acabada sobre nuestro pasado $y$, por ende, sobre nuestro presente. Rescatar a "Judíos de mi Infancia" es, para mí, hoy, afirmar que Sneh y Poch están presentes, en estado de memoria. 


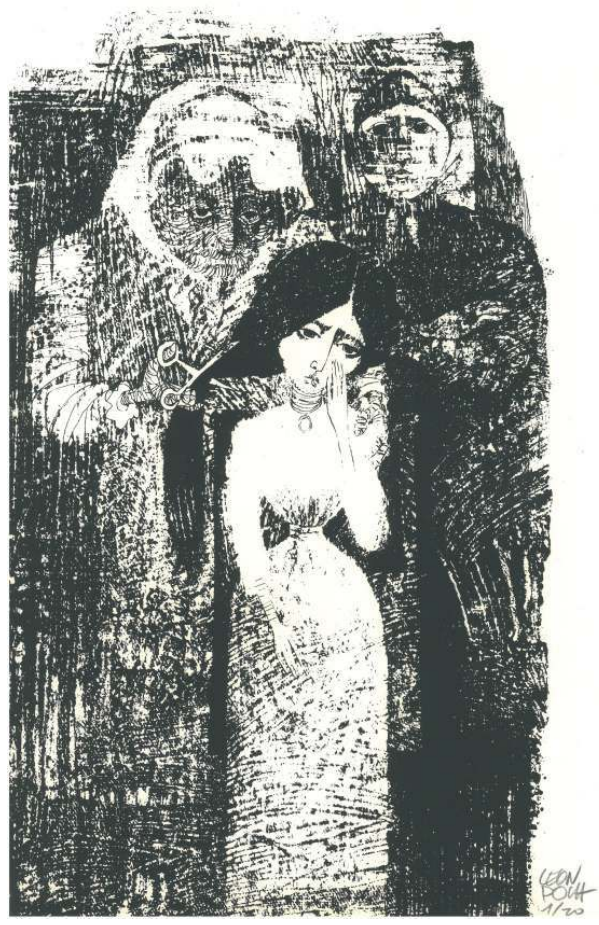

\section{La novia / Di kale}

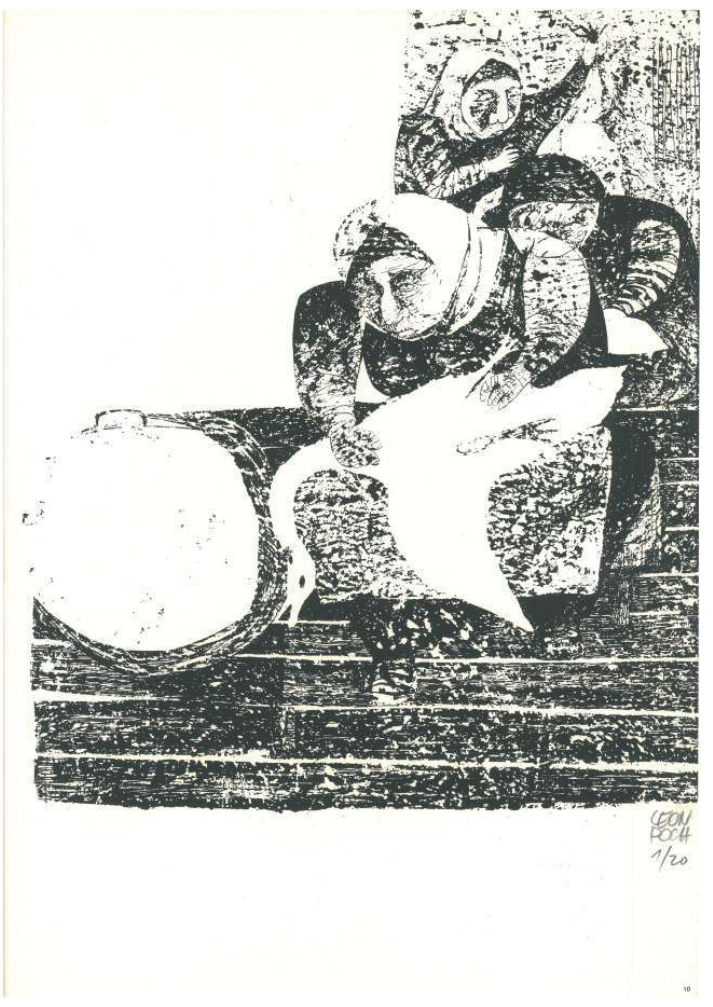




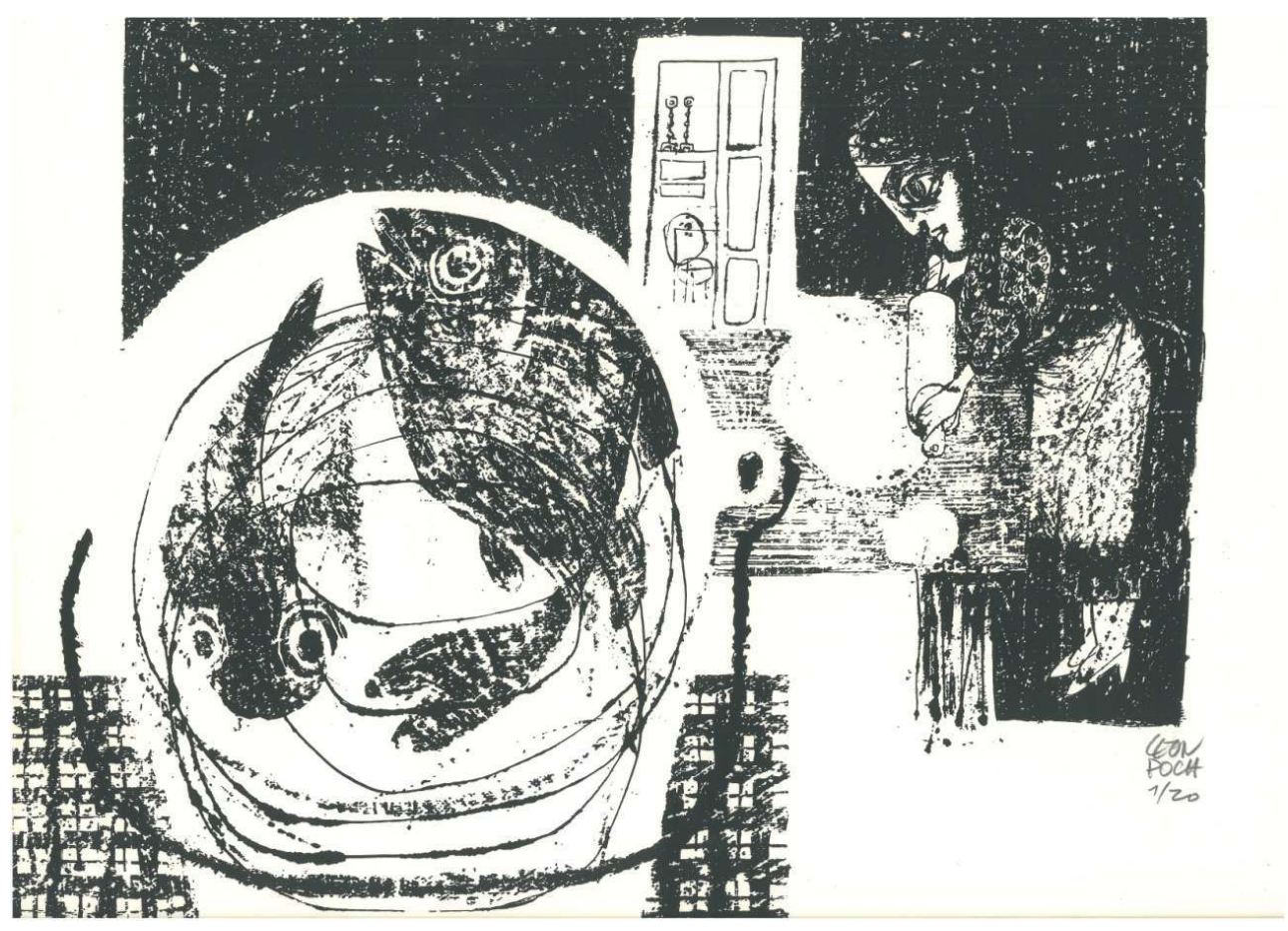

19. Preparativos para el sábado / Erev Shabes

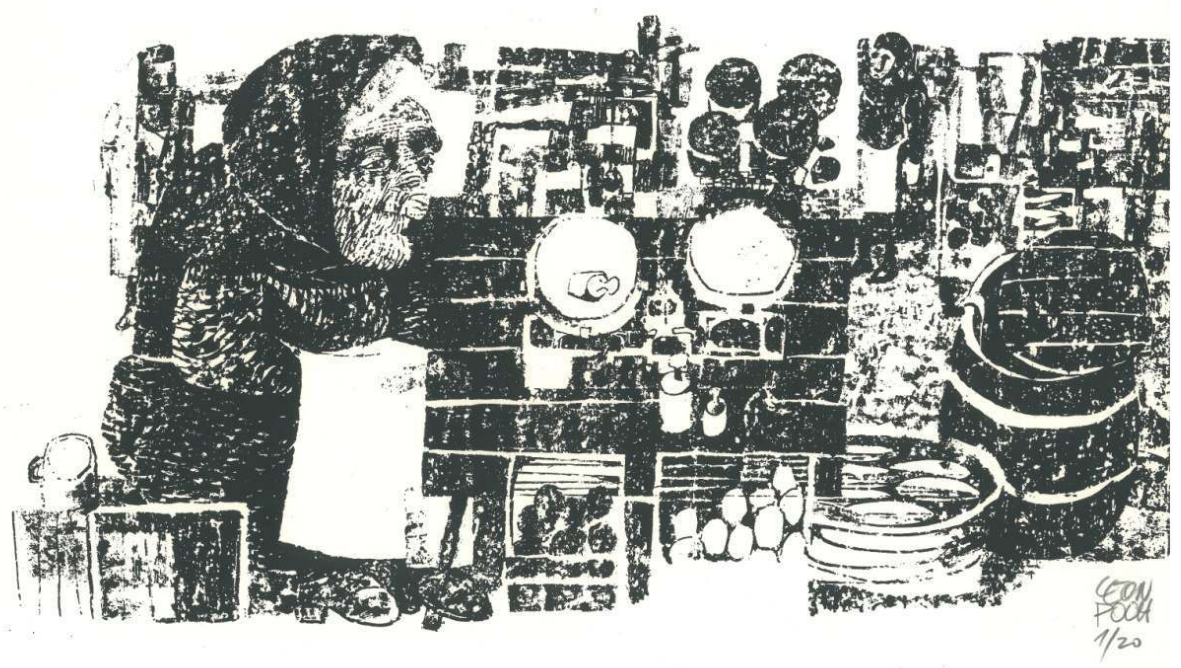



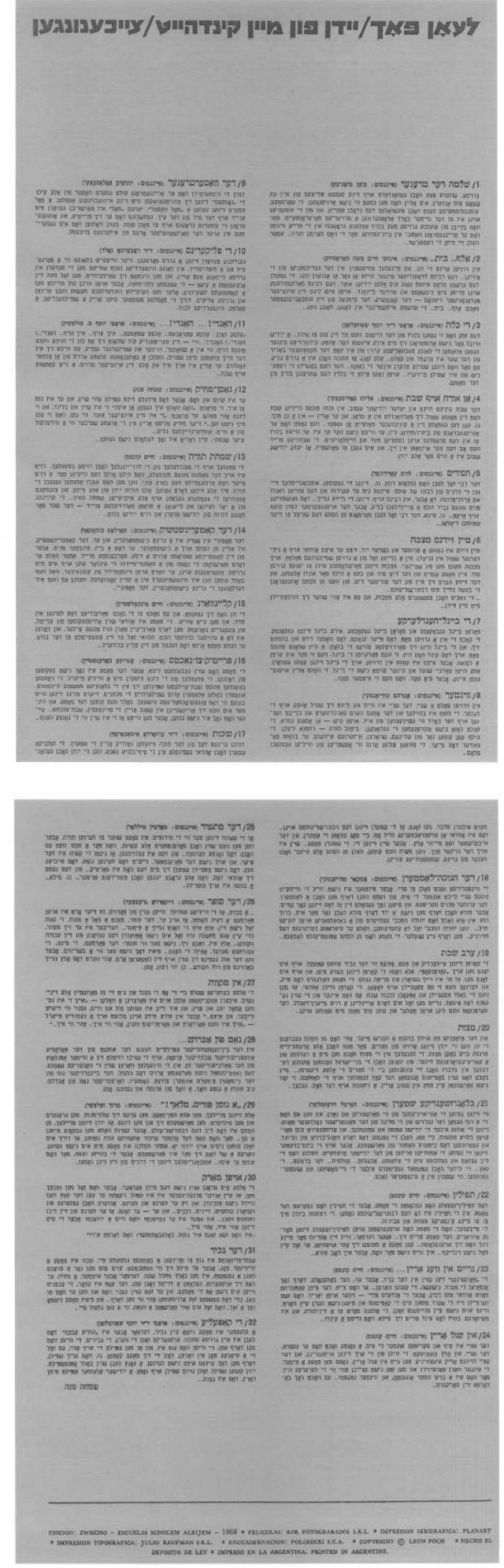

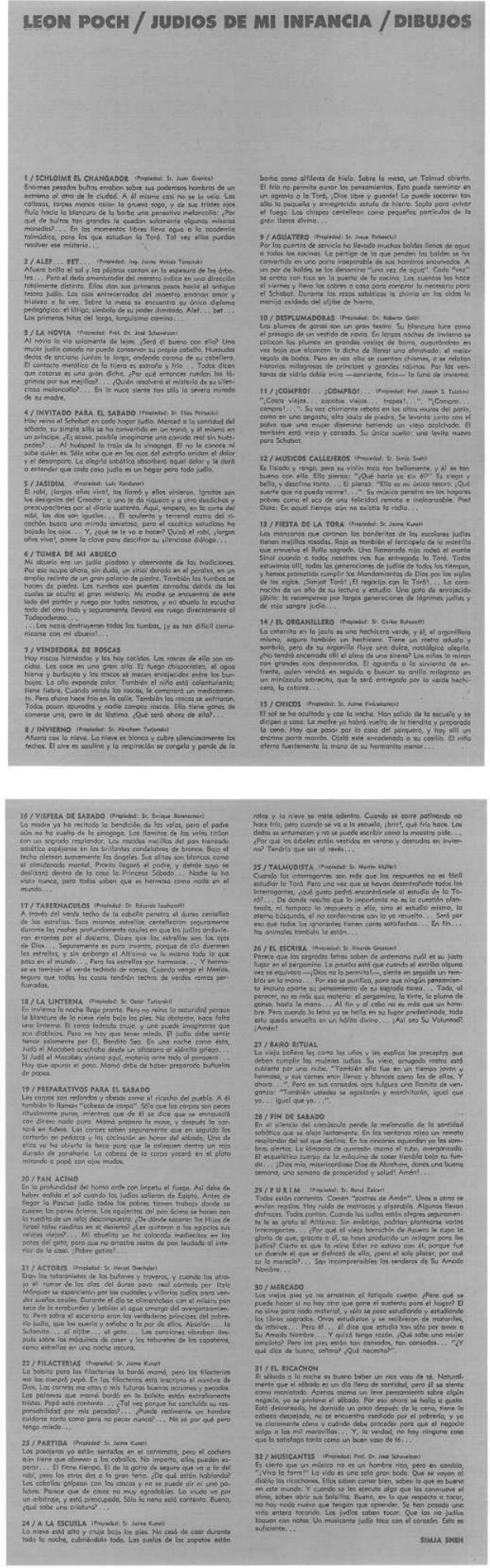


\section{BIBLIOGRAFÍA}

Aleijem Scholem, Estrellas errantes. Buenos Aires: Acervo Cultural, 1956.

Baczko Bronislaw, Los imaginarios sociales. Memorias y esperanzas colectivas. Buenos Aires: Ediciones Nueva Visión, 1999.

Benjamin Walter, Para una crítica de la violencia y otros ensayos. Iluminaciones IV. Madrid: Taurus Humanidades, 1991.

Bialik Jaim Najman, Der masmid, disponible en <https://www.yiddishbookcenter.org/collections/ yiddish-books/spb-nybc211246/bialik-haym-nahman-der-masmid>, página consultada el $24 / 01 / 2018$.

Eco Umberto, Decir casi lo mismo. Experiencias de traducción. Barcelona: Lumen, 2008

Feierstein Ricardo, Historia de los judíos argentinos. Buenos Aires: Ameghino editora S.A., 1999.

González Horacio, “Un soldado judío”. Sin Rumbo (Na ve’Nad). Antología. Buenos Aires: Biblioteca Nacional. 2015, p. 19.

Katz Dovid, «Yiddish» - YIVO Encyclopedia, 2010, disponible en <www.yivoencyclopedia.org/ article.aspx/Language/Yiddish>, página consultada el 01/04/2018.

LaCapra Dominick, Escribir la historia, escribir el trauma. Buenos Aires: Ediciones Nueva Visión, 2001.

Manguer Itzik, Pájaros nocturnos. Versión castellana e introducción: Simja Sneh. Buenos Aires: AMIA, 1975.

Onega Gladys S., La inmigración en la literatura argentina (1880-1910). Buenos Aires: Centro Editor de América Latina, 1982.

Poch León, Judíos de mi infancia/Dibujos. León Poj. Idn fun main kindhait / Tzeijenunguen. Buenos Aires: Edición Zwischo - Escuelas Scholem Aleijem, 1968.

Reisen Abraham, Mai ko mashmalon . New York: 1915., disponible en <https://www.loc.gov/item/ ihas.200186155>, página consultada el 20/01/2018.

Senkman Leonardo, El antisemitismo en la Argentina/1. Buenos Aires: Centro Editor de América Latina, 1986.

Sneh Perla (comp.), Buenos Aires Ídish. Buenos Aires: Gobierno de la Ciudad de Buenos Aires, 2006. Sin Rumbo (Na ve'Nad). Antología. Buenos Aires: Biblioteca Nacional. 2015.

---Palabras para decirlo. Lenguaje y exterminio. Buenos Aires: Paradiso, 2012.

Sneh Simja, Na-ve'Nad (Sin Rumbo). Ershter band. Forvort fun Jaim Finkelstein. Hile guetzeijnt Leó n Poj. Buenos Aires: Undzer Vort, 1952.

---Dos gueshrei in der najt (El grito en la noche) Buenos Aires: Editorial Undzer Vort, 1957.

---Breve historia del ídish. Buenos Aires: Biblioteca Popular Judía del Congreso Judío Latinoamericano, № 87. 1976.

---Sin Rumbo (Na ve’Nad). Buenos Aires: Editorial Milá, 1993. 
Sosnowski Saúl, La orilla inminente. Escritores judíos argentinos. Buenos Aires: Editorial Legasa, 1987.

Vinelli Elena, “Traducción intersemiótica: Revisión del debate de Bologna”. La Plata: Memoria académica, 2009, disponible en <http://www.memoria.fahce.unip.edu.ar/trab_eventos/ev.3630/ ev.3630.pdf>, página consultada el 23/01/2018.

Viñas David, Literatura argentina y realidad política. Buenos Aires: Centro Editor de América Latina, 1982.

Weinreich Uriel, “Yiddish Languaje”. Encyclopaedia Judaica. Israel: Keter, 1992. CD rom.

Yerushalmi Yosef Hayim, "Reflexiones sobre el olvido". Usos del Olvido. Comunicación al Coloquio de Royaumont. Buenos Aires: Ediciones Nueva Visión, 1989.

\section{NOTAS}

1. Cambió su nombre de Simja Itzjok Rozenblat a Simja Sneh, en 1943-4. Leibush Poj (Yehuda en hebreo) adoptó el nombre de León Poch, con la realización fonética de la "ch" castellana.

2. Zwischo: Zentrale Veltlej Ídishe Shul Organizatzie (Organización Central de Escuelas Laicas Judías). La Zwischo - Escuelas Scholem Aleijem fue creada por activistas e intelectuales del Poalei Sion de izquierda (movimiento sionista-socialista), llegados de Polonia a la Argentina. En 1934, abrió las primeras escuelas de la red. En 1940, inauguró el edificio de la escuela Scholem Aleijem con capacidad para 1.600 alumnos.

3. No hay un criterio único y normativo para transliterar el ídish a letras latinas. Suele usarse el código del YIWO (IWO -Ídisher Visnshaftlejer Institut- Instituto Científico Judío) de Nueva York, que se adapta a la fonética inglesa. Prefiero la transliteración adaptada a la fonética castellana, para facilitar el acceso a los lectores no familiarizados con el ídish.

4. Cada una de estas instancias planteará problemas teóricos y prácticos que sólo abordaré parcialmente en este trabajo.

5. Poj antplekt far undz dos vait-ekzotishe, un undz alemen azoi noente, land fun zain kindhait, velje iz oij gueven undzer alemens kindhait. Nota s/n y s/f. Gracias a mi hermana, Dina Poch, por el recorte. Traducción mía.

6. El número entre paréntesis indica el asignado en el álbum.

7. Mai ko mashma lon, publicado en ídish, en 1915.

8. Cf. nota 5. "[...][baim kukn oif Pojs tzejenungen] ij hob bejush derfilt, az ij hob zij umguekert in land fun main eiguener kindhait. Fun vait-noentn farshnitenem avar undzern iz aroisgueshvumen dos idishepoilishe shtetl, a lebediks, a batzirtm mit ale idishe jeinen, bahoijt mit dem din-bloilejn nepele fun melanjolisher dermonung, veljes nemt undz arum shtendik ven mir dermonen undzere taiere un noente, vos zenen avek fun undz un doj lebn zei in undzer guemit. Ez iz shver zij funandertzuklaibn derbai, tzi iz dos mer a benkshaft tzu di ale, vos lebn inem land fun undzere shotndike shlofloze nejt, oder iz dos a benkshaft tzu undzer eiguener,oif eibik farlozener kindhait. Obervi es zon nit in zijarum, bisn same letztn zain,veisn mir az mir trogn otem undzern, a gantze velt fun bilder, onunguen un guefiln."

9. Poch regresó a su ciudad natal en 1987. Visitó el cementerio de Sosnowiec. Estaba intacto.

10. En ídish, algunas veces el sonido "t" del hebreo se pronuncia "s".

11. Agradezco a Perla Sneh la información respecto de que nunca hizo estudios formales de castellano. A Ricardo Feierstein le debo el dato de que Sneh no dudaba en consultar, cuando le era necesario, con sus colegas hispanoparlantes. 


\section{RESÚMENES}

El momento y significación del encuentro entre los dibujos de León Poch y los textos escritos en ídish y traducidos al castellano por Simja Sneh, en el álbum Judíos de mi Infancia (Buenos Aires, 1968) constituyen el eje central de este trabajo. Si el recuerdo funda la cadena de la tradición que se transmite de generación en generación, las treinta y dos imágenes y los sesenta y cuatro textos se proponen restaurar el eslabón que la Shoah quebró. A través del arte, Poch y Sneh aspiran a crear un lugar de memoria y la proyección hacia el futuro de un pasado y una lengua -el ídishcuyos destinos perciben como inciertos.

Le moment et la signification de la rencontre entre les dessins de León Poch et les textes rédigés en yiddish et traduits en espagnol par Simja Sneh, dans l'album Judíos de mi Infancia [Juifs de mon Enfance] (Buenos Aires, 1968), constituent l'axe central de ce travail. Si le souvenir fonde la chaîne de la tradition transmise d'une génération à l'autre, ces trente-deux images et soixantequatre textes visent à restaurer le chaînon que la Shoah a brisé. À travers l'art, Poch et Sneh aspirent à créer un lieu de mémoire et la projection vers l'avenir d'un passé et d'une langue -le yiddish- dont les destins sont perçus comme étant incertains.

The moment and significance of the encounter between León Poch's drawings and the texts written in Yiddish and translated into Spanish by Simja Sneh in the album titled Judios de mi Infancia [Jews of my childhood] (Buenos Aires, 1968) represent the central concept of this work. If memories are the cornerstone of the chain of tradition transmitted from generation to generation, then the thirty-two images and the sixty-four texts are determined to restore the link broken by the Shoah. Through art, Poch and Sneh aspire to create a place of memory and a future projection for a past and a language -Yiddish- whose fates they consider uncertain.

\section{ÍNDICE}

Palabras claves: León Poch, Simja Sneh, Judíos de mi Infancia, ídish, memoria

Mots-clés: León Poch, Simja Sneh, Judíos de mi Infancia (Juifs de mon enfance), yiddish, mémoire

Keywords: León Poch, Simja Sneh, Judíos de mi Infancia (Jews of my childhood), yiddish, memory

\section{AUTOR}

\section{SUSANA POCH}

(ex) Universidad de Buenos Aires (Argentina) y Universidad de la República (Uruguay) susanapoch71@gmail.com 